\section{The Modified Widman Flap}

by

Sigurd P. Ramf JORd, * L.D.s., Ph.D.

Robert R. NisSLE,** D.D.S., M.S.

WIDMAN $^{1}$ INTRODUCED THE reverse bevel scalloping type of gingival incisions in 1916 as a modification of Neumann's ${ }^{2}$ periodontal flap surgery. Widman made a scalloped gingival incision around the neck of the teeth about $1 \mathrm{~mm}$. away from the teeth, raised a high mucoperiosteal flap beyond the apices of the teeth, curetted away the remaining soft tissue collar around the teeth, did a thorough root planing of the teeth, a minor trimming of bone for flap adaptation, and closed the flap by individual interproximal sutures. ${ }^{3}$ The procedure was a mode of treatment of periodontal pockets aimed at reattachment and readaptation of the pocket walls rather than surgical eradication of the outer walls of the pockets. Essentially the same procedure was described more recently by Morris. ${ }^{4}$

The Widman flap procedure with various modifications ${ }^{5}$ has been used off and on by one of the writers of this article for over 30 years with a rather unpredictable ratio between successes and failures until it was included in the Michigan longitudinal study $1966 .^{6}$

The present paper will be confined to description of technical details of the currently used modification of the Widman flap procedure and include a discussion of rationale related to current knowledge of periodontal biology.

\section{Surgical Procedures}

Following initial scaling, removal of gross overhangs and instruction in oral hygiene (hygienic or preparatory phase of periodontal therapy), at least 3-4 weeks should lapse before the modified Widman flap surgery is done. This will allow for healing and maturation of collagen in the inflamed gingiva and thus facilitate precise flap adaptation and optimal wound contraction towards the tooth surface postoperatively. The gingival shrinking following the hygienic phase also makes it easy to establish how far away from the tooth the initial incision should be placed in order to end up with an esthetically

*Professor and Chairman, Department of Periodontics, The University of Michigan School of Dentistry, Ann Arbor, Michigan 48104.

**Professor, Department of Periodontics, The University of Michigan School of Dentistry, Ann Arbor, Michigan 48104. pleasing thin gingival margin. Furthermore the need for mucogingival surgery can be more accurately assessed following the hygienic phase than at the time of the initial examination since an apparent gain of attached gingiva often occurs after the initial therapy.

The patient's face is washed thoroughly with an antiseptic soap and draped. The field of surgery is swabbed with an antiseptic such as mild tincture of iodine or iodine lotion* and the area to be operated is anesthetized. The initial incision is made with a Bard Parker \#11 or any other suitable knife that can be directed parallel to the long axis of the tooth. (Figure 1 ). If the buccal or lingual pockets are deeper than $2 \mathrm{~mm}$., this initial incision should be placed at least $1 / 2-1 \mathrm{~mm}$. away from the free gingival margin in order to assure removal of all crevicular epithelium since deep rete pegs often extends almost through a thin free gingiva and

*Phenol (5\%) 1 part; Aconite tinct-2 parts; iodine tinct-3 parts; glycerine-4 parts.

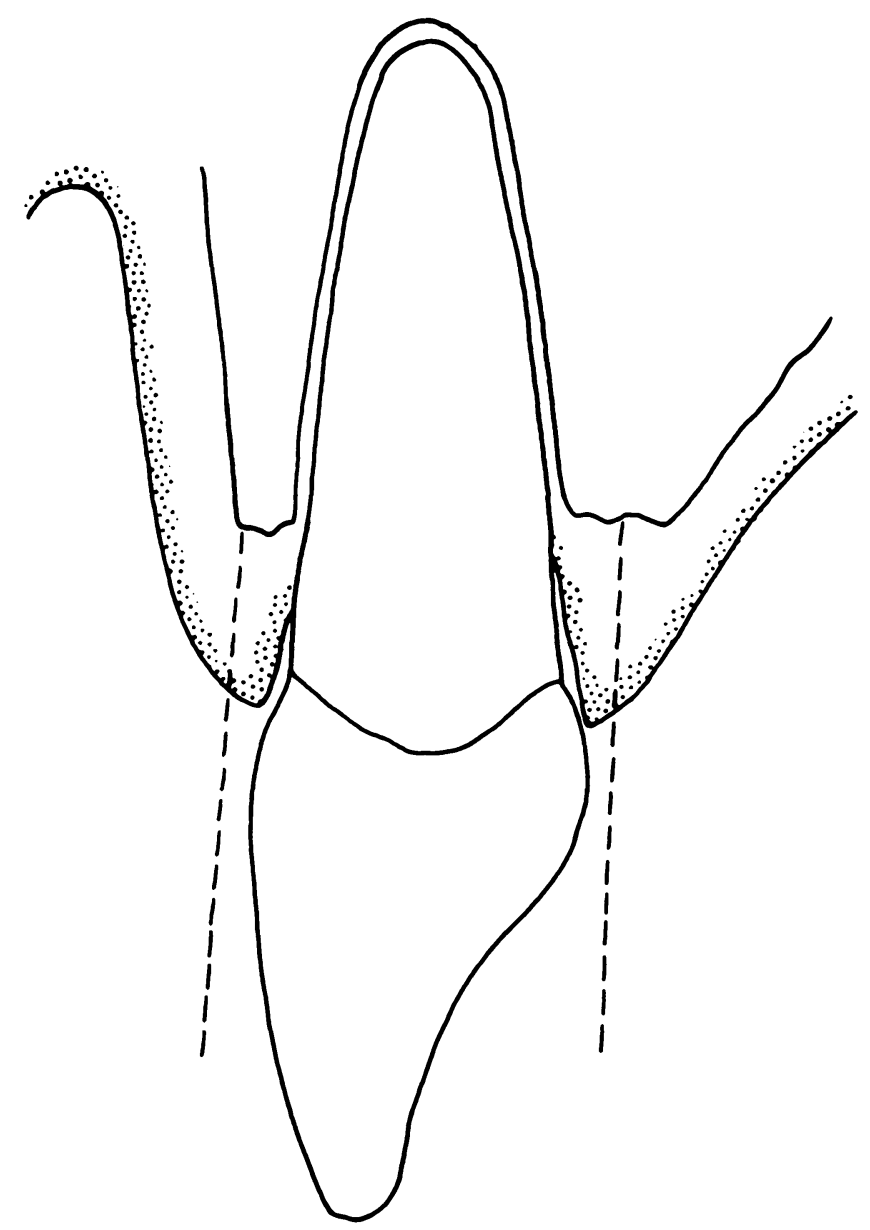

Figure 1. The dotted lines indicate the direction and position of the initial incision. 
would prevent reattachment of the pocket wall to the tooth.

When buccal pockets are shallow, and/or esthetic considerations are important, one may use an intracrevicular incision or incise at the free gingival margin (Figure 2).

The scalloping effect of the incision should be exaggerated on the palatal aspect in order to insure flap adaptation interproximally later (Figure 3 ). Also be sure to direct the scalpel slightly palatal to the long axis of the tooth aiming for the alveolar process $1-2 \mathrm{~mm}$. palatally to the alveolar crest (Figure 4), otherwise flap adaptation and flap contour will not be satisfactory.

It is important for postoperative flap adaptation to remove the very minimum of interproximal tissues needed for elimination of epithelial lining of the pockets. This is especially important from the palatal side since this flap cannot be stretched. However, in the middle of the interproximal areas the epithelial projections often come close to meet between the mesial and the distal

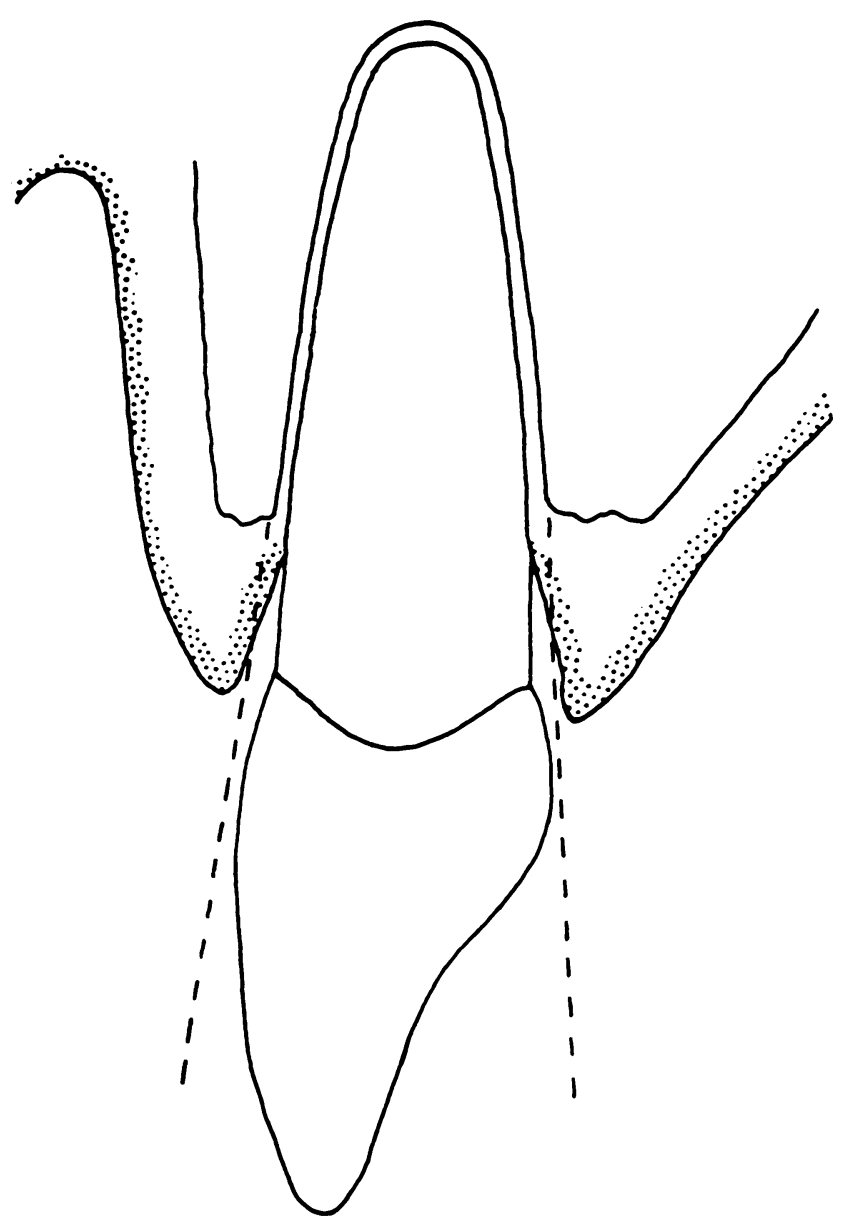

FIGURE 2. Intracrevicular incision indicated by dotted lines. Used for shallow pockets and thin free gingiva.

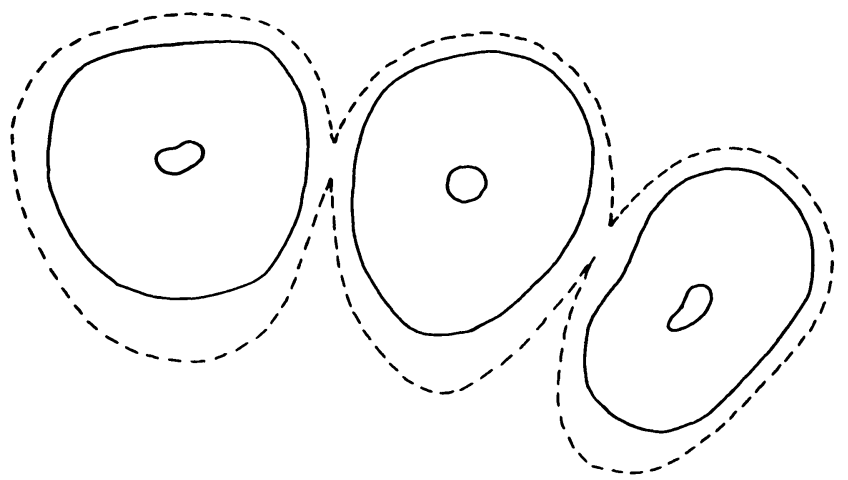

FIGURE 3. Schematic cross-section through maxillary front teeth. Dotted lines indicate the initial incision which will separate completely some of the interproximal areas from the future flaps. Note the exaggerated palatal scalloping effect. The interproximal flaps may overlap slightly after suturing.

aspects of the papillae (Figure 5). In order to promote connective tissue reattachment all interproximal structures infiltrated by epithelium must be removed. When the roots of the teeth are situated closely together it is

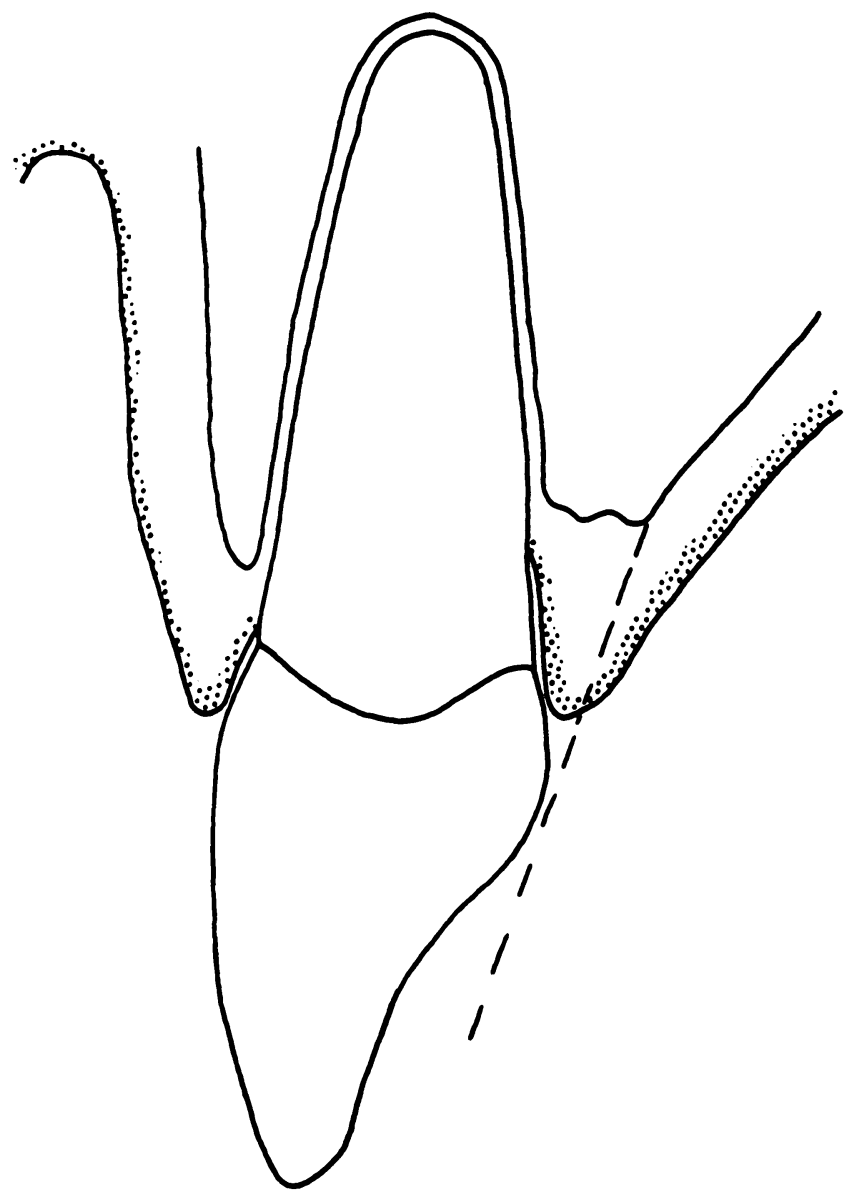

FIGURE 4. The dotted line indicates the reverse bevel character of the palatal incision in order to secure good contour and flap adaptation postsurgically. 
therefore advisable to make the initial incision in such a manner that some interproximal tissues remain with the collar of tissues which separates the flaps from the teeth (Figure 3).

Vertical releasing incisions through the interdental papillae and into the attached gingiva should be extended $2-3 \mathrm{~mm}$. apically to the initial incision at each end of the flap. Avoid vertical incisions in the palate in the second bicuspid, first and second molar areas. Use mucoperiosteal elevators to raise a full thickness flap only for $2-3 \mathrm{~mm}$. or the minimum needed to deflect the flap enough to gain later access to the surfaces of the teeth, to the alveolar crest and for the interproximal alveolar process. After the periosteum thus has been separated from the alveolar crest mechanically, the flap is allowed to rest against the bone to protect the bone from drying out.

A second incision is made around the neck of each tooth from the bottom of the crevice to the alveolar crest (Figure 6). The instruments used for the initial incision may also be used for the second incision. The third and last incision is done with a narrow interproxi-

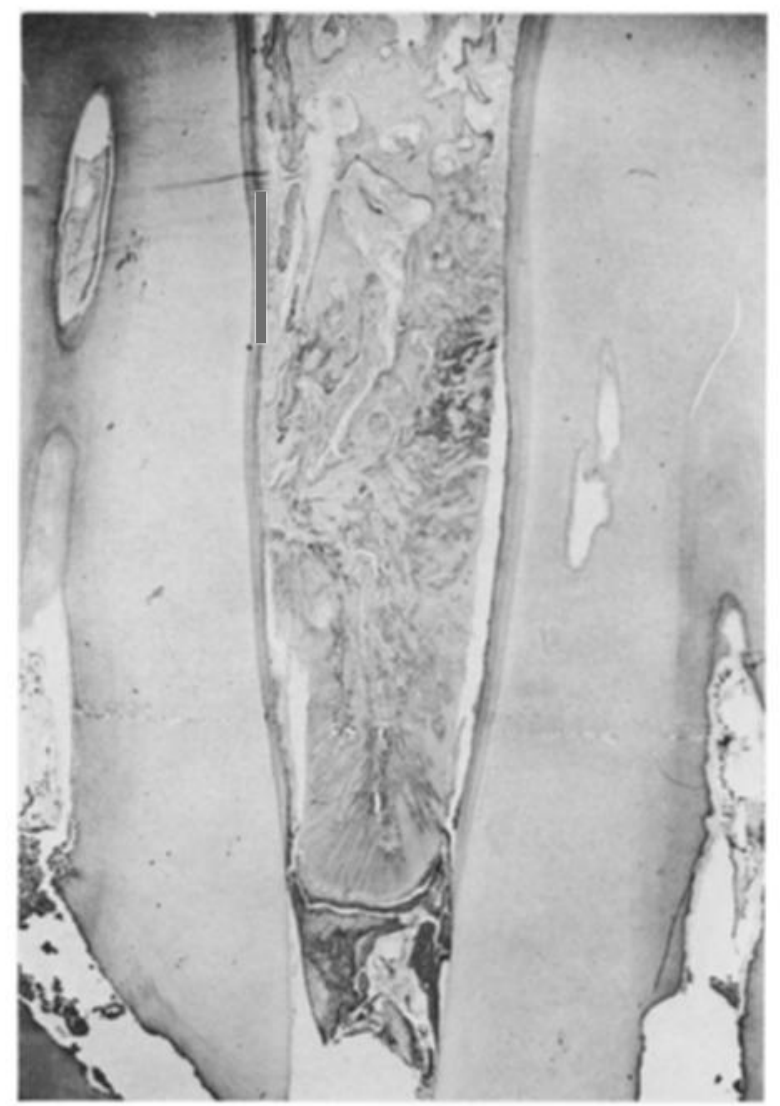

FIgURE 5. Photomicrographs of interproximal periodontal pockets between maxillary bicuspids. Note that the interproximal papilla is made up almost completely of epithelium. mal knife (f. ex. Orban knives which have been sharpened many times) (Figure 7). The buccal and lingual flaps are pushed aside so the interproximal knives can be placed on the alveolar process to cut loose the collar of gingival tissues which has been separated from the buccal or lingual flap and the teeth. This last incision follows the contour of the alveolar crest and the interproximal septum as much as possible.

The loosened collar of gingival tissues is then removed with sharp curettes. The part of the root surfaces that have been exposed in the periodontal pockets are thoroughly curetted and planed. However, where there is residual periodontal membrane attachment to the roots of the teeth close to the alveolar crest no curettement should be done. All soft tissues are removed from the bony surface of intrabony lesions. The curettement is done under the flaps without holding the flaps away from the bone for any length of time. Suction is used, and sterile saline solution from a syringe when needed for vision. Do not use sponges, and do not use tap water which is neither isotonic nor sterile. ${ }^{7}$ The common indiscriminate use of tap water in periodontal surgery is biologically indefensible.

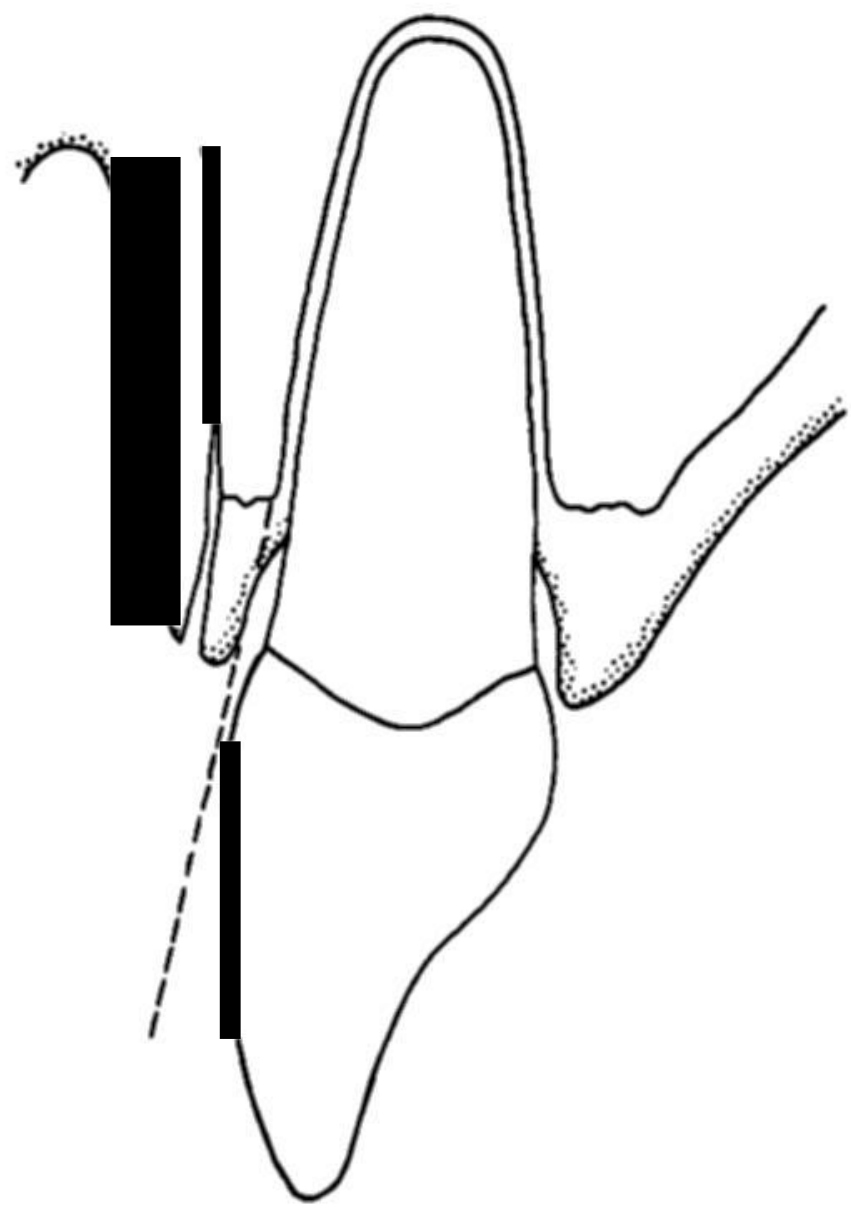

Figure 6. The dotted line indicates the direction of the crevicular second incision. 


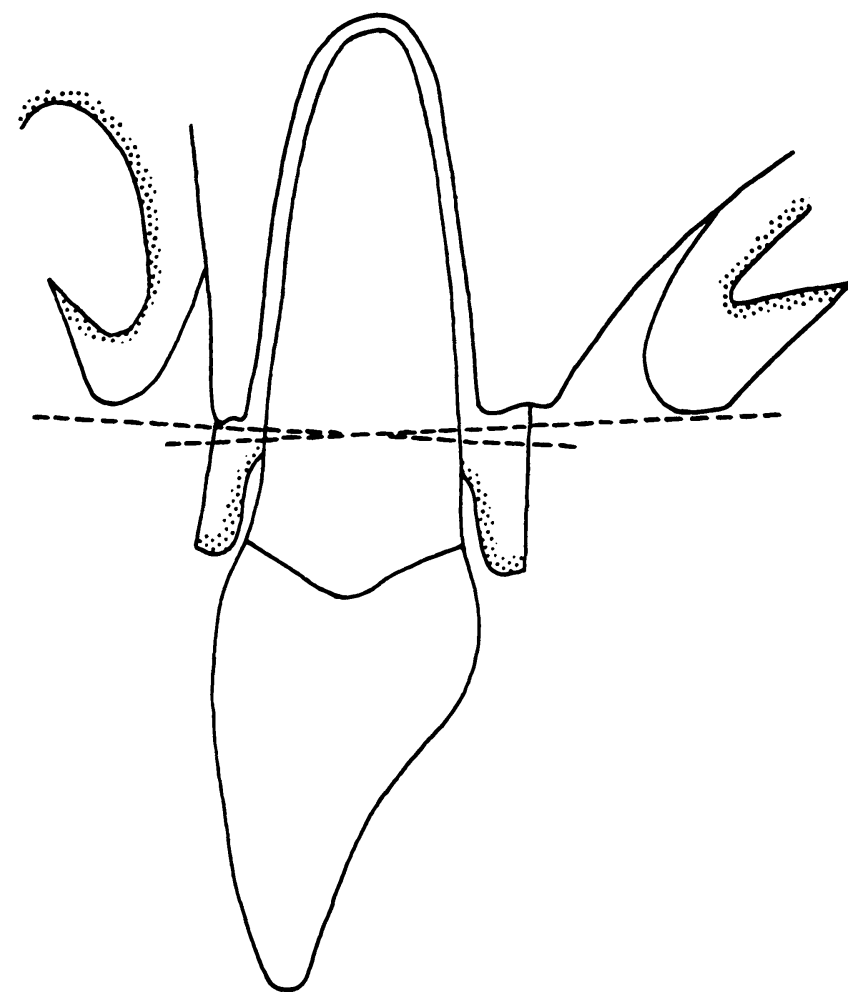

FIGURE 7. The labial and palatal flaps have been pushed aside, and the dotted lines indicate the supercrestal third incision.

The flaps are adapted to the bone and to each other interproximally with finger pressure. If the adaptation between the flaps and the teeth or between the buccal and lingual flaps are incomplete, the flaps have to be thinned and some bone may be removed from the outer aspects of the alveolar processes in order to enhance the flap adaptation.

Suture the flaps together with individual interproximal sutures. Do not take deep bites with the suture needed, because the interproximal flap margins may then fold and prevent primary healing (Figures $8 \mathrm{~A}, 8 \mathrm{~B}, 8 \mathrm{C}$ ). Do not use uninterrupted sutures since they do not provide as accurate flap positioning as the individual sutures and if an uninterrupted suture should slip loose in one area the flap position may be affected for other areas also.

If silk sutures are used, place antibiotic ointment over the sutures and place a firm periodontal dressing in such a manner that the buccal and lingual flaps are held tightly against the bone without exerting interproximal pressure on the flaps.

The dressing is removed after one week, the teeth polished and the patient instructed in oral hygiene. If the healing is not complete in a week because of poor flap adaptation, such an area is cleaned with a curette and a new dressing is placed.

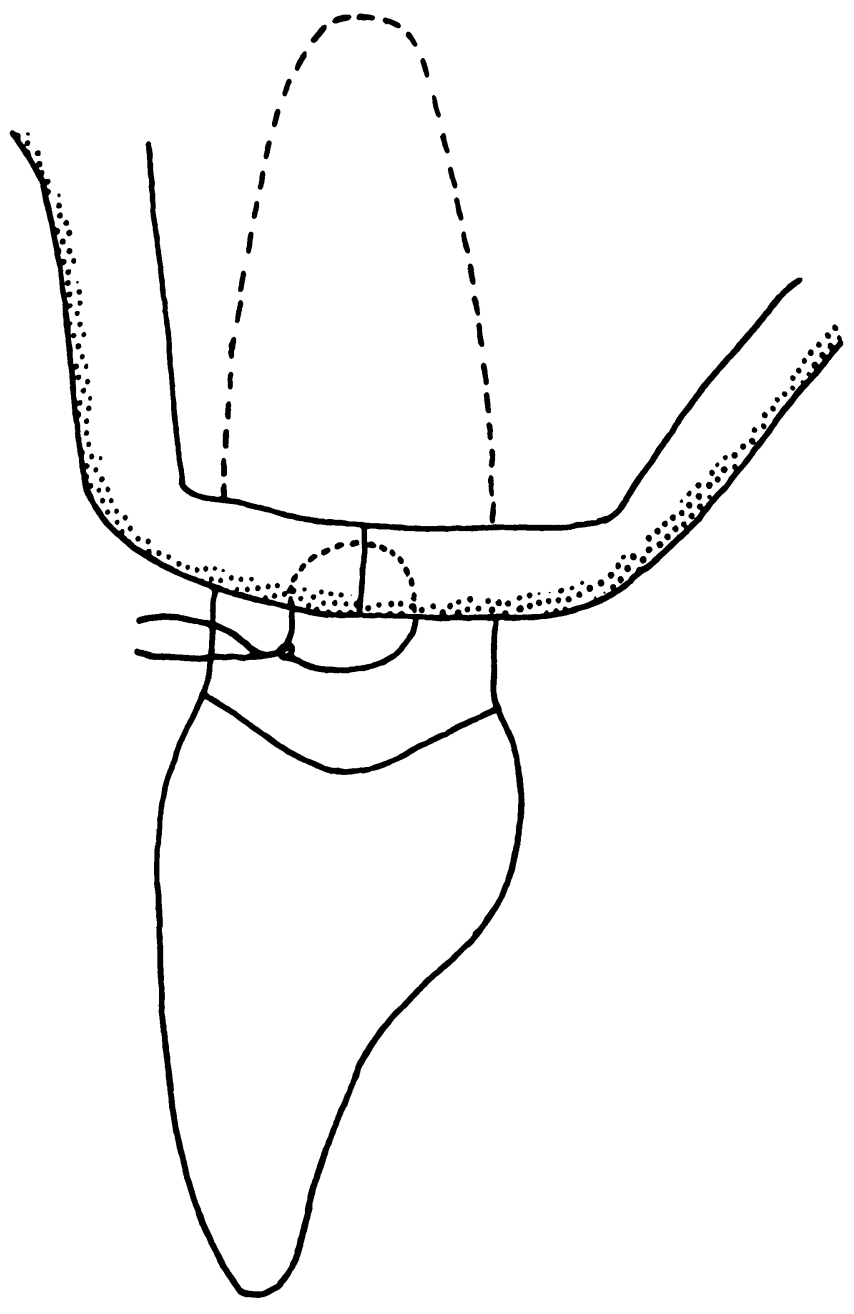

FIGURE 8a. Correct suturing and flap adaptation.

\section{Summary of THE MOdifications OF THE WIDMAN FLAP}

The described modifications of the Widman flap surgery differs from the original design only in the following refinements:

1. The initial incision is parallel to the long axis of the teeth and the flaps are separated from the bone to a lesser extent than in the original Widman flap in order to avoid unnecessary bone resorption. Whenever a flap is raised, full or partial thickness, there will be some bone resorption, ${ }^{8}$ and since the only purpose of the flap is to get full access to the exposed roots of the teeth and the alveolar and interproximal bony surfaces, limited flap separation from the alveolar process is needed.

2. The collar of tissues around the necks of the teeth is cut loose with sharp knives (second incision) instead of tearing with curettes. Thus excessive curettement on root surfaces with intact perio- 


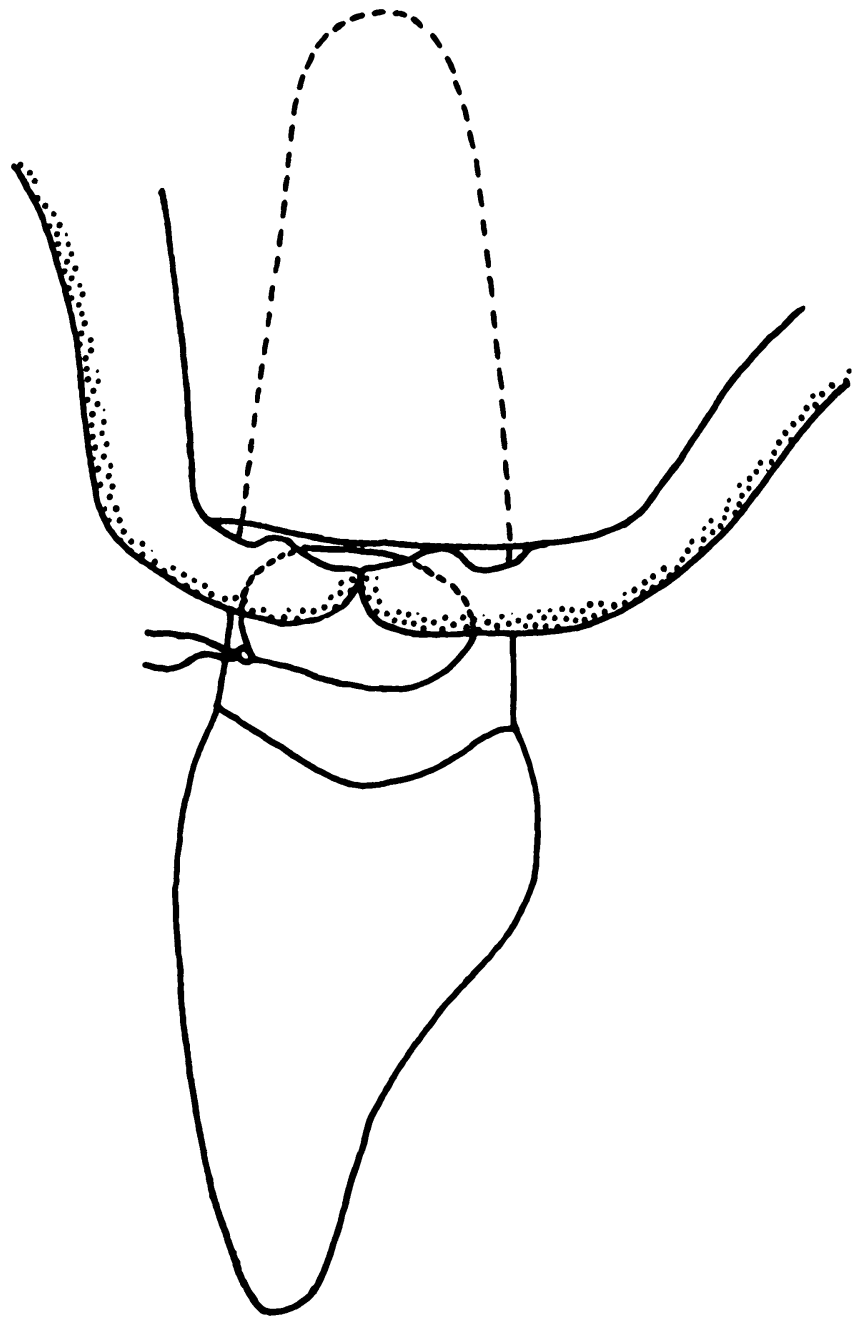

Figure 8b. Too deep bites of sutures and interproximal folding of the flap.

dontal fiber attachment is avoided. Flap healing to a root surface with remaining periodontal fiber attachment has been demonstrated to be optimal and prompt ${ }^{9}$ while a connective tissue attachment may or may not occur to an instrumented tooth surface. ${ }^{10}$ The third incision also is a modification allowing removal of the collar of tissues around the teeth without trauma to the alveolar crest and interproximal bone. It is important that the interproximal knives are used with delicate care since such knives may easily produce grooves in the root surface which later may enhance plaque retention if reattachment of fibers does not take place. $^{10}$

3. Close interproximal flap adaptation requiring exaggerated palatal scalloping of the flaps is given much more attention than in the original Widman procedure.

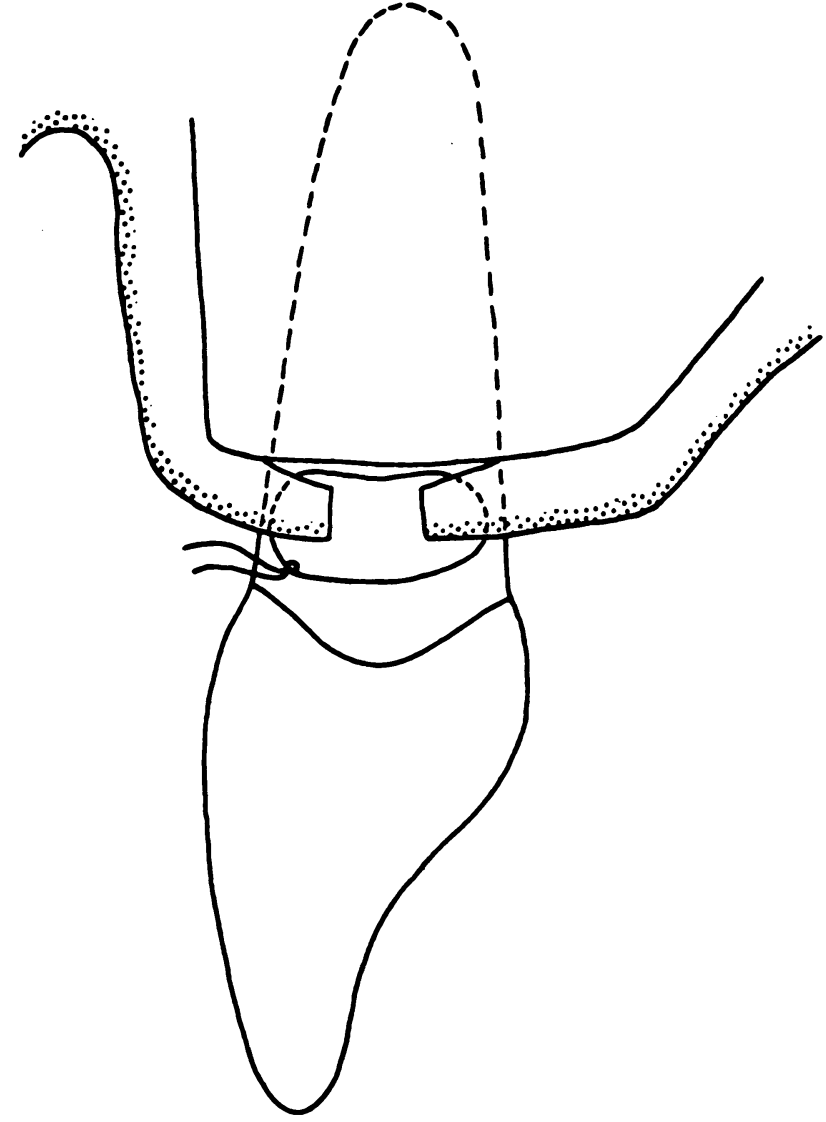

FIGURE 8c. Interproximal flaps too short. Inadequate coverage of bone and minimal chance for reattachment.

\section{Rationale, Advantages and Disadvantages of the MODIFIED WIDMAN FLAP}

The main advantage of the modified Widman flap surgery over any other periodontal surgical procedure is the intimate postoperative adaptation of healthy collagenous tissues to all tooth surfaces. It has been shown experimentally in animals ${ }^{11}$ and humans that with a close adaptation of gingival tissues to the tooth surface, a marginal new epithelial attachment forms which tends to seal off the deeper areas of separation between the tooth and the surrounding tissues. ${ }^{12}$ Thus the healing connective tissues may adapt as closely to the tooth surfaces as to an implant, ${ }^{13}$ and reattachment with formation of new cementum may develop gradually from the apical aspects of the lesion. In such cases minimal or no inflammation is present indicating that the pathologic periodontal pocket has been eliminated as a source of irritation. Apparently, some such areas may gradually develop a very long epithelial attachment ${ }^{14}$ which with continuous irritation may open up as a pathologic pocket again. It is well established that reattachment may occur 
following lateral sliding flaps and the interproximal tissues are biologically identical to the labial tissues. Thus with equally good flap adaptation interproximally as obtained buccally in lateral sliding flaps, interproximal reattachment can be obtained.

With the conventional types of reverse bevel flaps, with or without apical positioning, the interproximal bone and tooth surfaces are usually left denuded. ${ }^{15}$ Eventually, such an area will granulate over and healing occur at a more apical level than following a well adapted modified Widman flap. ${ }^{16}$ Therefore in order to achieve pocket elimination and less return of pocket depth, the conventional type of reverse bevel flap surgery utilizes much more bone removal than the Widman flap surgery. The modified Widman flap surgery is not aimed at surgical eradication of pocket walls, including bony walls. It is aimed at maximum healing in areas of previous periodontal pockets with minimum loss of periodontal tissues during and after the surgery. It must be emphasized that failure in approximating completely the buccal and lingual flaps or inadequate fit of the flaps to the teeth following attempts to perform modified Widman flap surgery often gives poor results with residual inflamed and deep periodontal pockets. Thus if the initial incision comes out faulty it may be better to change over to a conventional reverse bevel flap surgery with a thin and apically positioned flap and to do bone removal as needed for pocket elimination.

Bone may fill into an intrabony lesion following a wide variety of periodontal procedures and such a result is most desirable. However, it has been found that in many instances where the bone has not filled in to any appreciable extent judged from repeated roentogenograms over several years there may not appear any indication of further bone loss although a thin probe may be inserted deeply along the tooth surface without bleeding and/or pain in the area of the previous pocket. ${ }^{16}$ While in other areas with obviously inflamed recurrent periodontal pockets there is continuous loss of bone. It thus appears that the modified Widman flap surgery may be very successful in maintaining periodontal support and health by mechanisms of a long epithelial attachment, and connective tissue adaptation, with or without reattachment of connective tissue, and with or without regeneration of bone. Such successfully treated areas with close adaptations without connective tissue reattachment may in part be opened up temporarily by probing with a thin probe, without the presence of an active or progressive periodontal pocket.

The obvious advantage of the modified Widman flap surgery, compared with conventional reverse bevel flap surgery with bone surgery for pocket elimination, is that it is conservative of bone and optimal coverage of root surfaces by soft tissues which is esthetically desirable, and facilitates oral hygiene. Lesser exposure of root surfaces also means potentially less root sensitivity and fewer caries problems. Modified Widman flaps also appear to result in more pocket closure and more regeneration of bone than conventional reverse bevel flap surgery. ${ }^{17}$

One apparent disadvantage of the modified Widman flap procedure is the unfavorable interproximal architecture immediately following removal of the dressing. However, if meticulous oral hygiene is maintained, the interdental tissues will regenerate with gain rather than loss of attachment as measured clinically from the cementum-enamel junction with a calibrated probe. ${ }^{16}$

The merits of the modified Widman flap surgery may be compared with subgingival curettage. Actually, the modified Widman flap surgery may be considered a modification of subgingival curettage with the raising of flaps, assuring better access to the root surfaces and a better control of removal of the pocket lining with a lesser mechanical trauma to the gingival tissues than during curettage. However, curettage has the advantage of not directly affecting the bone. Preliminary data from a longitudinal study indicates fairly similar results following both these methods. ${ }^{6} \mathrm{~A}$ main consideration for both procedures certainly is the requirement of advanced technical skills of the operator. Access for root planing and removal of interproximal pocket lining without undue soft tissue trauma are problems in subgingival curettage which are better handled by the modified Widman flap approach. However, perfect interproximal adaptation of the flaps also demands meticulous accuracy. Results from clinical trials comparing results from modified Widman flaps and other surgical procedures will be published at a later date.

\section{SUMMARY}

The following modifications of the Widman flap surgery have been described:

1. Initial incision parallel to the long axis of the teeth.

2. Raising the mucoperiosteal flap only $2-3 \mathrm{~mm}$. from the alveolar crest.

3. Crevicular incision around the neck of the teeth.

4. Surgical excision of the collar of tissues around the teeth.

5. Exaggerated palatal scalloping for close interproximal flap adaptation.

\section{REFERENCES}

1. Widman, L.: The operative treatment of pyorrhea alveolaris. A new surgical method. Sv. Tandl. Tidsk., Dec., 1918. 
2. Neumann, R.: Die Alveolarpyorrhoe und ihre Behandlung. Hermann Meusser, Berlin, 1920. Third ed. (First edition was published 1911, second edition 1915). These were not available.

3. Everett, F. G., Waerhaug, J. and Widman, A.: Leonard Widman: Surgical treatment of pyorrhea alveolaris. J. Periodont., 42:571, 1971.

4. Morris, M. L.: The unrepositioned muco-periosteal flap. Periodontics, 3:147, 1965.

5. Ramfjord, S. P.: Reinsercion. Rev. Ass. Odont. Argentina, 47:275, 1959.

6. Ramfjord, S. P.: Clinical trials of therapeutic measures in periodontics. Int. Dent. J., 21:16, 1971.

7. McEntegart, M. G. and Clark, A.: Colonization of dental units by water bacteria. Brit. Dent. J., 134:140, 1973.

8. Wood, D. L., et al.: Alveolar crest reduction following full and partial thickness flaps. J. Periodont., 43: $141,1972$.

9. Levine, H. L.: Periodontal flap surgery with gingival fiber retention. J. Periodont., 43:91, 1972.
10. Ramfjord, S. P. and Costich, E. R.: Healing after simple gingivectomy. J. Periodont., 34:401, 1963.

11. Caffesse, R. G., Ramfjord, S. P. and Nasjleti, C. E.: Reverse bevel periodontal flaps in monkeys. J. Periodont., 39:219, 1968

12. Sullivan, H., Carman, D., and Dinner, D.: Histological evaluation of the laterally positioned flap. \#467. I.A.D.R. abstracts 1971 .

13. Bodine, R. L., and Mohammed, C. J.: Histologic studies of a human mandible supporting an implant denture. Part II. J. Prosth. Dent., 26:415, 1971.

14. Levine, H. L., and Stahl, S. S.: Repair following periodontal flap surgery with the retention of gingival fibers. J. Periodont., 43:99, 1972.

15. Prichard, J. F.: Advanced Periodontal Disease. 2nd ed. Philadelphia, Pa., W. B. Saunders Co., 1972.

16. Ramfjord, S. P., et al.: Longitudinal study of periodontal therapy. J. Periodont., 44:66, 1973.

17. Kelly, G. P.: Relationships radiographic bone height, pocket depth and attachment level in a longitudinal study of periodontal disease. Ann Arbor, The Univ. of Mich., 1973. viii +76 p. typed thesis.

\section{Announcements}

\section{NORTHWESTERN UNIVERSITY DENTAL SCHOOL}

Northwestern University Dental School announces the following continuing education course:

Periodontics I.

Faculty: Dr. Henry Crossetti

Dates: December 11-12, 1974

The rationale for periodontal therapy and the techniques involved will be presented. Emphasis will be placed on the role of definitive periodontal therapy in total sequential patient care.

For further information contact: Dr. Clifford Miller, Northwestern University Dental School, 311 East Chicago Avenue, Chicago, Illinois 60611 .

\section{VIRGINIA COMMONWEALTH UNIVERSITY MEDICAL COLLEGE OF VIRGINIA SCHOOL OF DENTISTRY}

The Medical College of Virginia School of Dentistry announces the following continuing education course:

\section{Periodontics in General Practice}

Faculty: Staff of the Department of Periodontics

Dates: December 11-12, 1974

In this course the objectives and techniques employed in conservative periodontal therapy will be discussed, and the practitioner will be given an opportunity to examine a patient, render a diagnosis, and perform conservative periodontal therapy.

For further information contact: Dr. F. B. Wiebusch, Virginia Commonwealth University, Medical College of Virginia School of Dentistry, P.O. Box 637, Richmond, Virginia 23298.

\section{TUFTS UNIVERSITY SCHOOL OF DENTAL MEDICINE}

Tufts University School of Dental Medicine announces the following continuing education course:

How to Adjust the Occlusion for the Natural Dentition

Faculty: Drs. Max J. Perlitsh, Milton Dines, Abraham Haddad and Judith E. Mejias

Date: December 6, 1974

In the past ten years new information based upon research has supplanted many of our traditional assumptions regarding occlusion. Concepts like centric occlusion, hinge axis, and lateral excursion have not entirely withstood the scrutiny of new electronic telemetry of the dentition in actual function. This course will explain and demonstrate how to adjust the occlusion based upon most recently developed information in this field.

For further information contact: Program of Continuing Education, Tufts University School of Dental Medicine, One Kneeland St., Boston, Mass. 02111.

\section{UNIVERSITY OF PENNSYLVANIA SCHOOL OF DENTAL MEDICINE}

The University of Pennsylvania School of Dental Medicine announces the following continuing education course:

\section{CURRENT CONCEPTS IN PERIODONTOLOGY \\ Dates: November 18, 19, 1974 \\ Faculty: Henry M. Goldman, Dean, \\ Boston University School of Dentistry}

For further information contact Division of Continuing Education, University of Pennsylvania School of Dental Medicine, 4001 Spruce Street, Philadelphia, Pa. 19104 